\title{
Comparison of Two Different Electricity Tariffs for a Residence in Sivas, Turkey
}

\author{
Ahmet Fertelli* \\ Department of Mechanical Engineering, Cumhuriyet University, Sivas, Turkey \\ A.Fertelli (0000-0003-2279-1918)
}

\begin{abstract}
In this study, single- and multi-rate electricity tariffs for a residence in Sivas province were compared. Consumption in the residence was determined by examining the 5-year electricity bills of the house calculated based on pricing for the single-rate electricity tariff and the cost was calculated based on pricing for the multirate electricity tariff. The calculations revealed that monthly electricity consumption in the residence ranged between $220 \mathrm{kWh}$ and $280 \mathrm{kWh}$. If the current consumption is priced using a multi-rate tariff, the energy cost will be reduced by only $7 \%$. Electricity consumption habits should be supported by awareness-raising programs, and peak and day time electricity demand should be reduced by shifting electricity consumption to night hours.
\end{abstract}

Keywords: Single-multi time rate tariff, Electricity consumption, Energy efficiency

\section{INTRODUCTION}

In recent years, there has been a significant increase in demand for electricity both in the world and in our developing country. Meeting this demand with regional and national means plays an important role in terms of Turkey's energy security and energy policies. The demand for electricity in Turkey increased by $100 \%$, from $125,000 \mathrm{GWh}$ in 2000 to 275,000 GWh in 2016 [1]. Total electric energy consumption which was $554 \mathrm{kWh}$ per capita in 1980 increased to 3288 $\mathrm{kWh}$ per capita in 2014 [2]. Therefore, to meet electricity demand, it is very important not only to install new electric power systems and renewable energy systems such as solar, wind and biomass but also to efficiently use electricity generated at present and to save energy. Consumption of electricity energy varies from one hour to another during the day. Energy investments and distribution of power should be designed so as to meet the highest demand during the day. To achieve this goal, additional power plants should be installed, or electricity consumption should be shifted from the hours when the demand is highest to the other hours of the day when the electricity is cheapest. The analysis of the hourly electricity demand demonstrated that the demand increased up to $38000 \mathrm{MW}$ between $6 \mathrm{a}$.m. and 12 noon, and was $33000 \mathrm{MW}$ between 6 p.m. and 11 p.m [3]. In order to reduce the changes in electricity demand, the Electricity Market Law published in the Official Gazette dated August
10, 2002 changed the tariffs in the Electricity Market Tariff Regulations to shift the consumption of electricity to the hours when demand for electricity was low [4]. Electricity generation companies price electricity bills on one- and three-rate tariffs. In the three-rate tariff, the period between 6 a.m. and 5 p.m. was regarded as daytime, between 5 p.m. and 10 p.m. as peak time and 10 p.m. and 6 a.m. as nighttime [5]. In the three-rate tariff, the electricity price is approximately equal to that in the one-rate tariff during the daytime, is the highest during the peak time, and is the cheapest during the nighttime. Figure 1 shows the amounts of peak-time demand and the increase rates according to years. The peak-time demand for electricity increased more than twofold from 2000 to 2016. As shown in Figure 2, 24\% of electricity $(51,085,627.94 \mathrm{MWh})$ is consumed at homes [1]. Therefore, it is clear that if electricity consumption at homes is shifted to night time, households can significantly reduce their energy bills.

\section{MATERIAL METHOD}

According to the data released in 2016, in the province of Sivas, 1,099,824.54 MWh of electricity was consumed [1]. Of this amount, 49,993.17 MWh was consumed for lighting, 318,070.88 MWh at homes, 29,683.25 MWh for agricultural irrigation, 396,653.72 MWh in industry and 305,423.52 MWh in places of business [1]. In Sivas, the amount of electricity consumed at homes accounts for $28.92 \%$ of the total
*Corresponding authour

Email: fertelli@cumhuriyet.edu.tr
European Mechanical Science, March 2019; 3(1): 37-40 doi: https://doi.org/10.26701/ems.508021

Received: January 4, 2019

Accepted: March 4, 2019 


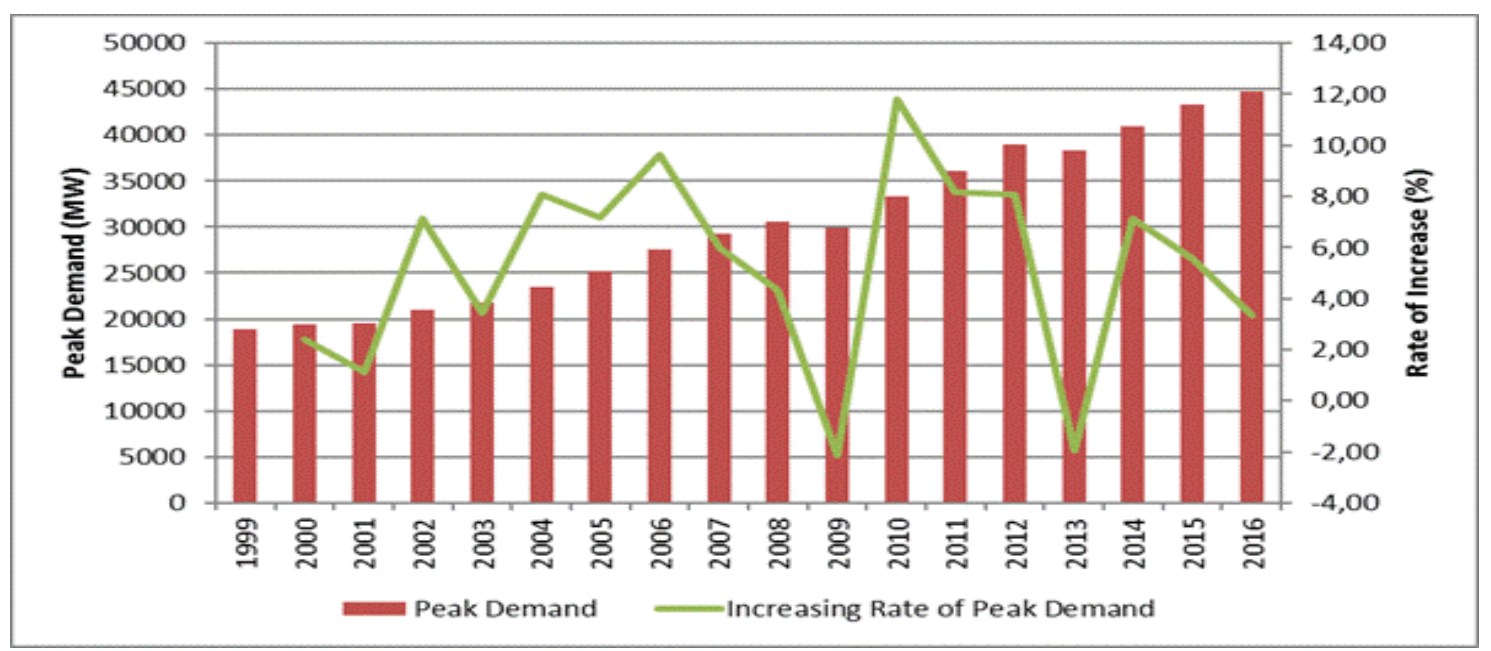

Fig. 1 The amounts of peak-time demand and the increase rates according to years [1]

consumption. The study was conducted in a standard family residence where 4 people live in the province of Sivas. In the house, there was a washing machine, a dishwasher, a television, a built-in set, an oven, an iron and a computer. There is no cooling system. The house is heated with a natural gas heating boiler. The electricity meter is a smart meter and can measure electricity consumption for 3 different times (daytime, peak time and nighttime). Although the electricity consumption is measured with a 3-rate meter, the electricity bill is charged on the single-rate tariff. Calculations were based on the 60-month electricity consumption values measured between 2012 and 2016 and on the amount of money paid for the electricity bills during that period. The amount of money to be paid was also calculated according to the multi-rate tariff and it was compared with the amount of money paid according to the single-rate tariff. It was also checked how electricity consumption differed between nighttime, daytime and peak time for 5 years.

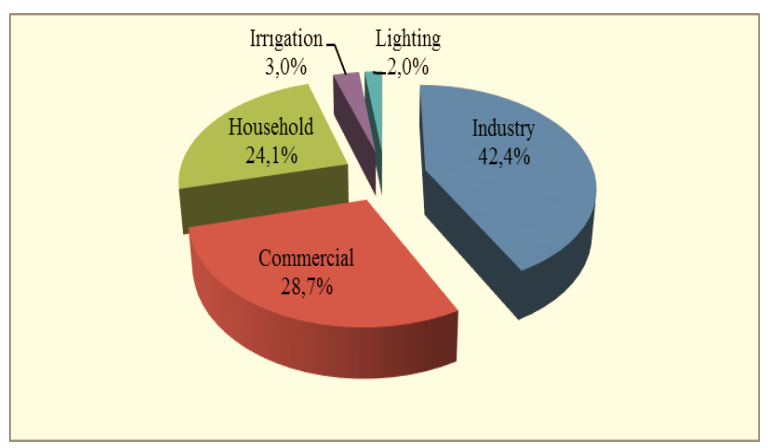

Fig. 2 Distribution of invoiced consumption by consumer type in 2016 [1]

\section{RESULT AND DISCUSSION}

Distribution of electricity consumption in three different periods in the house for all the years is shown in Figure 3.The highest daytime electricity consumption (between 6 a.m. and 5 p.m.) was in February, July and August in all the years and was generally between $100 \mathrm{kWh}$ and $150 \mathrm{kWh}$ per month.

The peak time electricity consumption (between 5 p.m. and 10 p.m.) varied between $60 \mathrm{kWh}$ and $100 \mathrm{kWh}$ per month. The nighttime electricity consumption (between 10 p.m. and 6 a.m.) was a little higher than was the peak time electricity consumption. These consumption values indicate that the households consumed electricity in the daily life without any intention to save money. Approximately $45 \%$ of the total electricity consumed is consumed in the daytime, whereas the remaining amount is consumed during the 5-hour peak time and 8-hour nighttime almost equally.
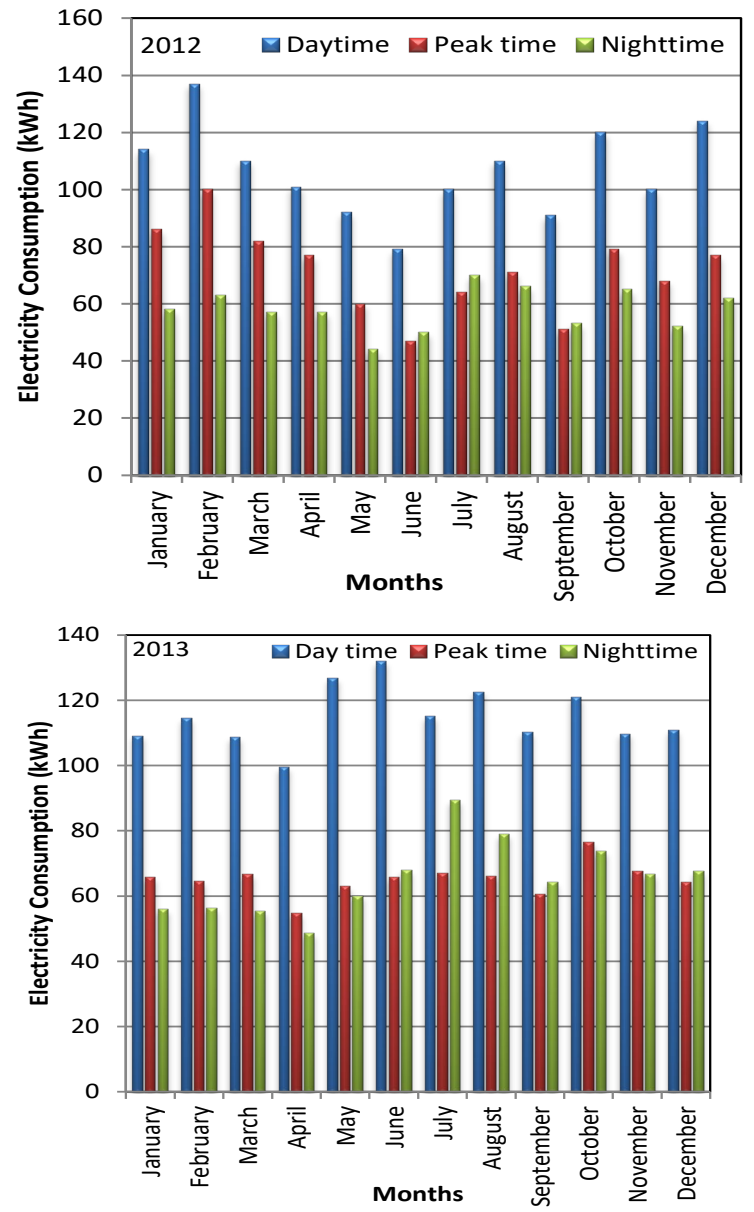

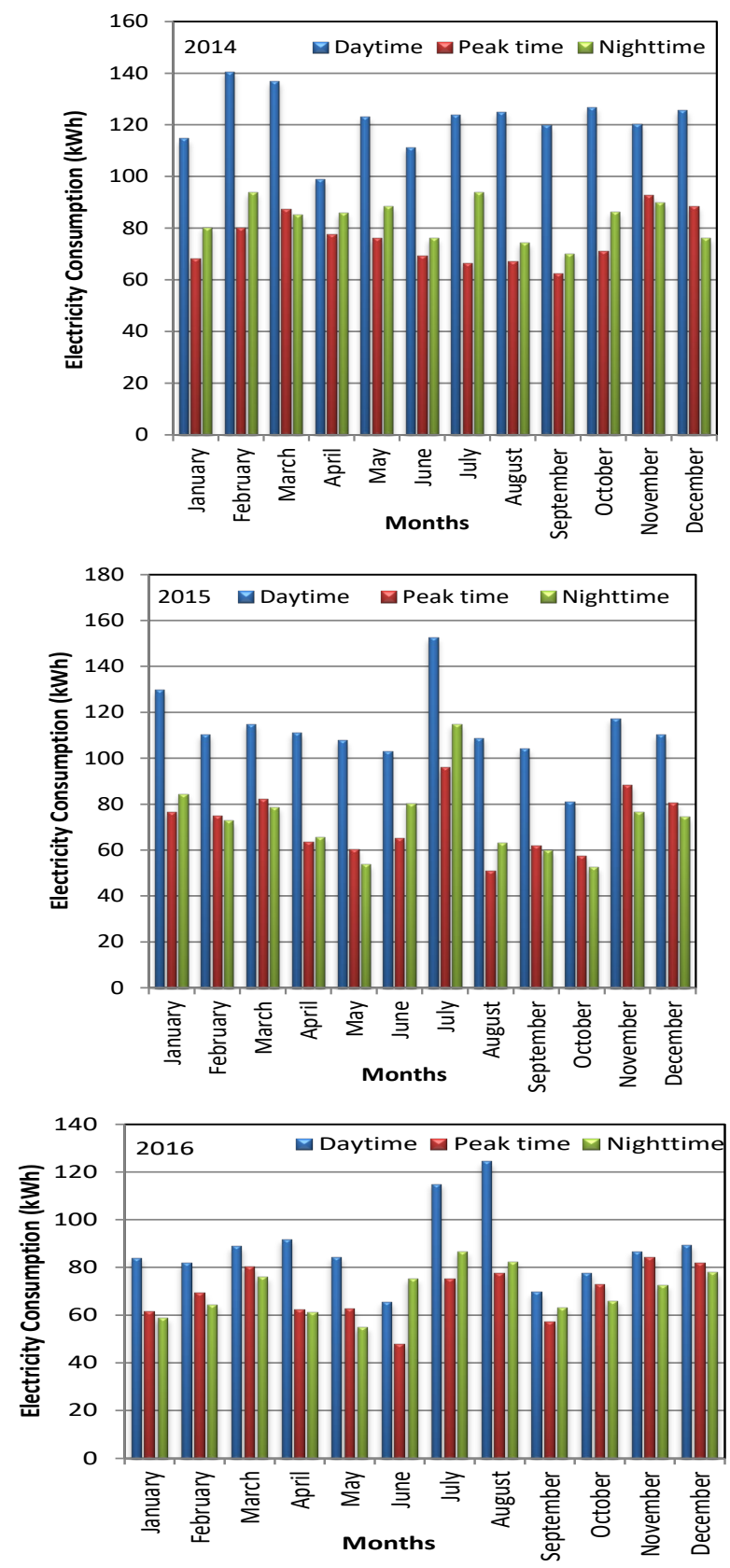

Fig. 3 Distribution of electricity consumption in three different periods in the house for all the years

Figure 4 shows the comparison between the actual monthly payments between 2012 and 2016 according to the single-rate tariff and the possible monthly payments if they were calculated according to the three-rate tariff. The bills cost from $¥ 60$ to $¥ 100$ in 2012 and 2013, and from $€ 80$ to $¥ 140$ between 2014 and 2016. In all the graphs, it is seen that the billing amounts for single and three-rate tariffs were very close to each other but that the single-rate tariff was a little higher in all the years, except 2012 and 2016. In these years, three-rate tariff bills were higher.

The comparison of 5-year bills calculated according to the single-rate tariff with those calculated according to the three-rate tariff based on the smart meter measurements showed that if the households' current electricity consumption habits are not changed and their peak time and daytime consumptions are not shifted to nighttime, multi-rate tariffs will not lead to any savings in bills. In fact, as noted in previous statements, the three-rate tariff might sometimes increase the cost of the bills.
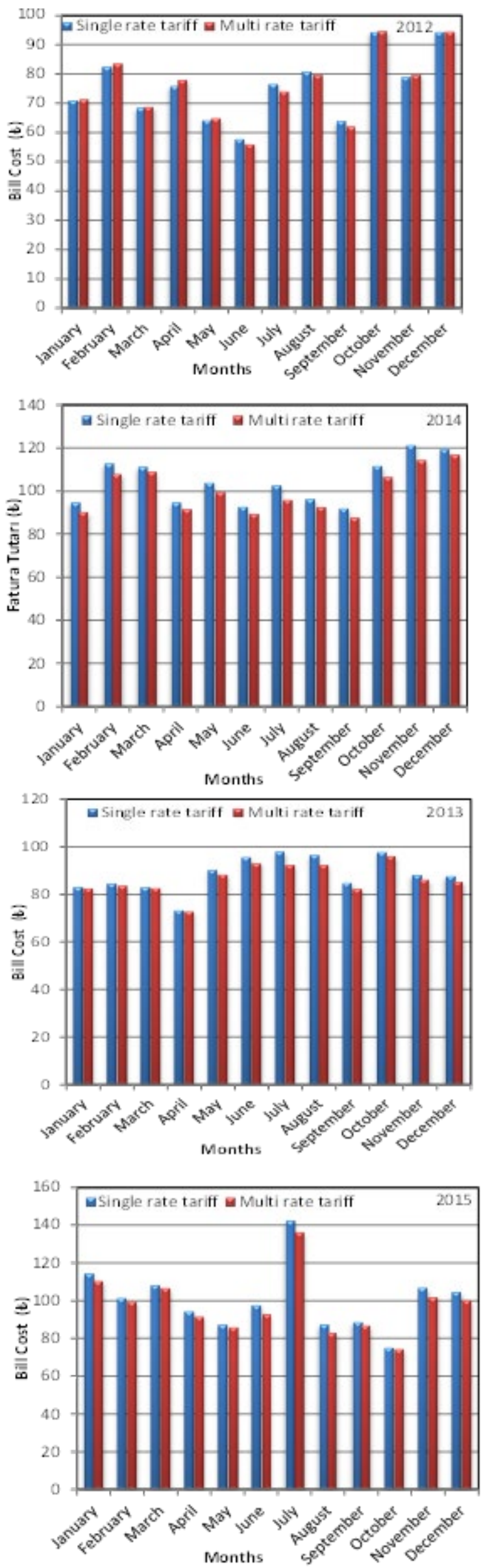


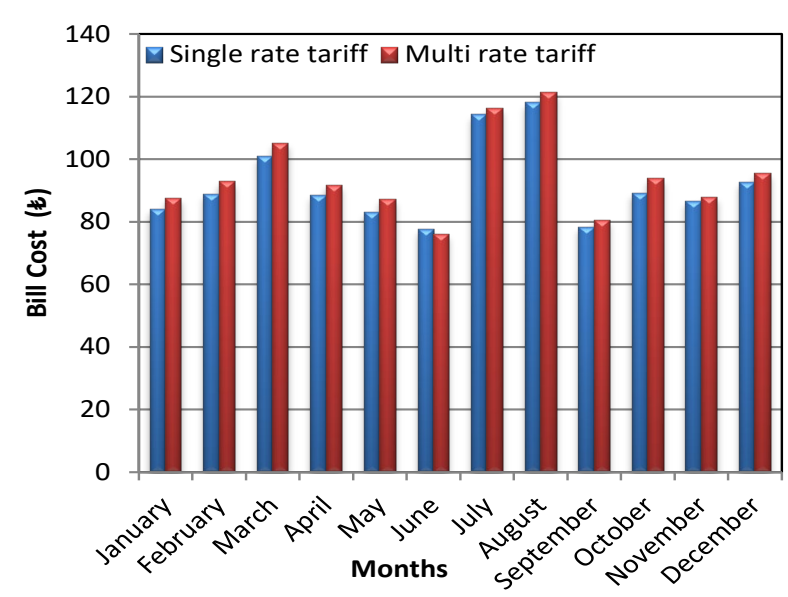

Fig. 4 The comparison between the actual monthly payments between 2012 and 2016 hest, which in turn will be to the advantage of the individual consumers because they will pay less. According to the results obtained from the present study, the households in the house where the research was conducted were not aware of single-rate and three-rate tariffs although they had a smart meter, which suggests that consumers' awareness of tariffs and differences in pricing should be raised. In addition, current consumption patterns do not make a significant change in the bills calculated with the single-rate and multi-rate tariffs; therefore, awareness-raising programs should be held to raise consumers' awareness of advantages and disadvantages of their electricity consumption habits. In order for current tariffs to be more attractive for the use of electricity in houses, the difference between the peak time and nighttime consumption should be repriced to encourage consu-

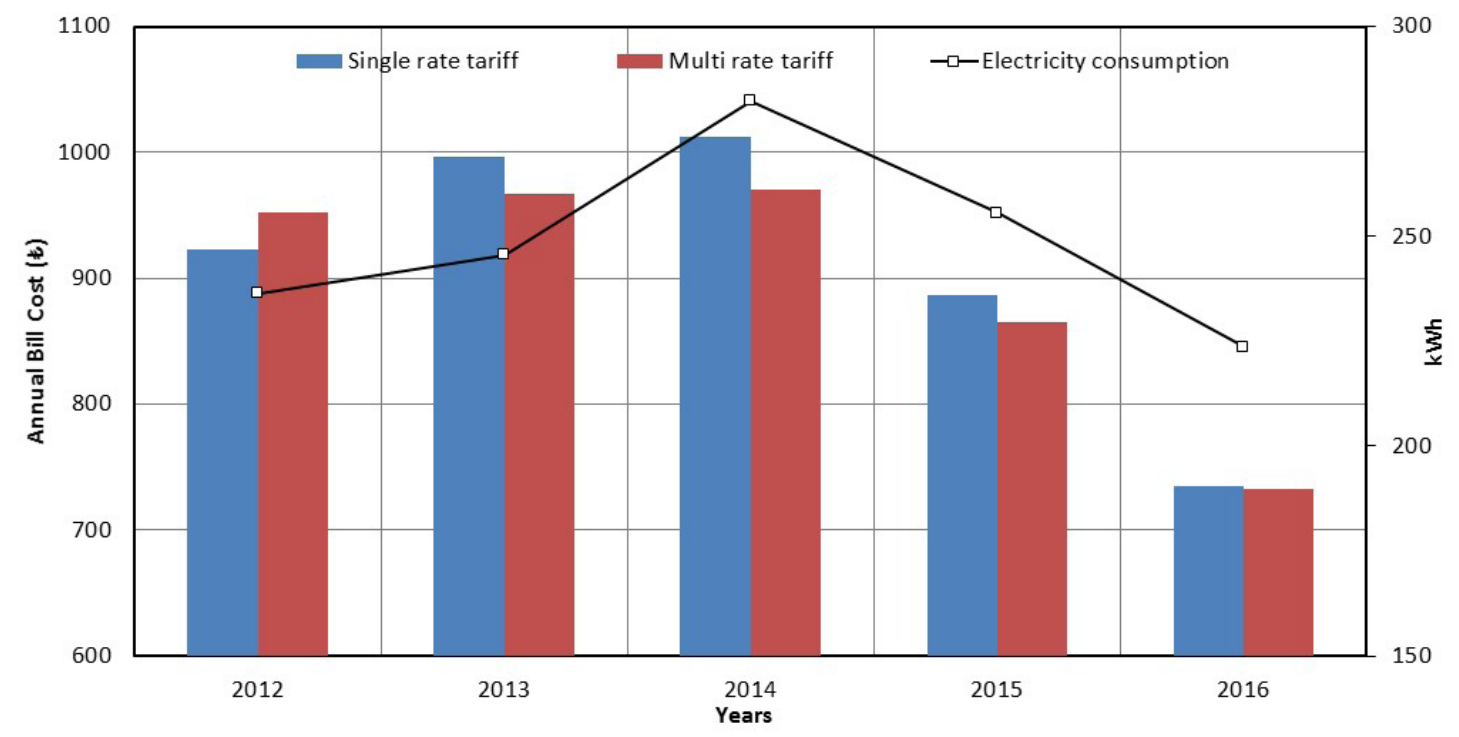

Fig. 5 The annual total bill amounts and annual average electricity consumption

Figure 5 shows the annual total bill amounts and annual average electricity consumption for the house. When the billing amounts for the multi-rate tariff are calculated according to the current consumption values, the billing amounts within the two different tariffs do not change much. There was a $5 \%$ to $7 \%$ difference between the bills for all the years. The multi-rate tariffs for the current electricity consumption did not lead to a substantial advantage. There was not a substantial difference between the costs calculated with the two different tariffs because the electricity consumption during the peak time and daytime was not shifted to the nighttime. Average electricity consumption values ranged from 220 $\mathrm{kWh}$ to $280 \mathrm{kWh}$ per month.

\section{CONCLUSIONS}

The need to reduce energy consumption in Turkey is not only due to inadequate electricity generation. It may also be realized by saving of current energy which is more economical. As the results indicate, shifting electricity consumption hours from peak time to nighttime when the electricity prices are the cheapest would lead to a decrease in peak time consumption when the electricity prices are the hig- mers to use electricity during nighttime.

\section{REFERENCES}

[1] Republic of Turkey Energy Market Regulatory, Turkish Electricity Market Sector Report 2016.Available:http://www.epdk.org.tr/TR/ Dokumanlar/Elektrik/YayinlarRaporlar/ElektrikPiyasasiGelisimRaporu.

[2] Ozcan M. (2018). The role of renewables in increasing turkey's self-sufficiency in electrical energy, Renewable and Sustainable Energy Reviews, 82(3): 2629-2639, DOI: 10.1016/j.rser.2017.09.111.

[3] Ministry of Energy and Natural Resources. Available: http://www. enerji.gov.tr File/?path=ROOT/1/Documents/E\%C4\%BOM\%20Periyodik\%20Rapor/Ocak\%C5\%9Eubat\%20B\%C3\%BClteni_son.pdf.

[4] Electric Tariff Regulation. Available:http://www.resmigazete.gov.tr/ eskiler/2002/08/

[5] 20020811. html.

[6] Yumurtacı Z., Dönmez A.H. (2013). Energy efficiency on household appliances. Mühendis ve Makina, 34(637):38-43. 